\title{
Analysis of disease profile, and medical burden by lead exposure from hospital information systems in China
}

\author{
Han Song ${ }^{1,2+}$, Jianchao Liu ${ }^{1 \dagger}$, Zipeng $\mathrm{CaO}^{2}$, Wenjing Luo ${ }^{2}$ and Jing-Yuan Chen ${ }^{1,2^{*}}$
}

\begin{abstract}
Background: Though lead (Pb)-gasoline has been banned for decades in China, Pb continues to be a vital risk factor for various diseases. Traditional studies, without large sample size, were unable to identify explicitly the associations among $\mathrm{Pb}$, its disease profile, and the related medical burden. This study was designed to investigate: 1) current status of blood Pb levels; 2) Pb-associated disease profile, medical burden, as well as impact factors.
\end{abstract}

Methods: Research subjects were patients who visited military hospitals and were required to test their blood $\mathrm{Pb}$ levels by doctors between 2013 and 2017. The large sample size and area coverage may, to a large extent, reveal the characteristics of Pb exposure in the whole Chinese population. Information of patients' electronic medical records was extracted using Structured Query Language (SQL) in Oracle database. The spatial, temporal, and population distribution of their blood $\mathrm{Pb}$ levels were tested, to illustrate the association of $\mathrm{Pb}$ exposure with diseases' profile, and medical burden. Non-parametric tests were applied to compare the differences of Pb levels among various groups.

Results: The blood Pb concentration showed a positively skewed distribution by Kolmogorov-Smirnov test $(\mathrm{D}=0.147, p<0.01)$. The blood Pb concentration of Chinese patients was $28.36 \mu \mathrm{g} / \mathrm{L}$, with the lowest blood Pb levels, $4.71 \mu \mathrm{g} / \mathrm{L}$, found in patients from Guangxi Zhuang Autonomous Region, and the highest, $50 \mu \mathrm{g} / \mathrm{L}$, in Yunnan province. Han Chinese patients' Pb levels were significantly lower than other minorities groups ( $z$-score $=-38.54, p<0.01$ ). Average medical cost for $\mathrm{Pb}$ poisoning was about $6888 \mathrm{CNY}$ for Chinese patients. Pb levels of patients with malignant neoplasm of lung, $45.34 \mu \mathrm{g} / \mathrm{L}$, were far higher than malignant neoplasm of other respiratory, and intrathoracic organs, $24.00 \mu \mathrm{g} / \mathrm{L}(\mathrm{z}$-score $=-2.79, p<0.01)$.

Conclusions: This study reported current status of blood $\mathrm{Pb}$ levels for patients who once visited military hospitals, partially representing the whole Chinese population. The result shows that Pb poisoning is still imposing marked economic burdens on patients under $\mathrm{Pb}$ exposure. Association of $\mathrm{Pb}$ with lung cancer may open up new areas for $\mathrm{Pb}$-induced toxicology. The research strategy may advance toxicological studies in the aspect of medical data mining.

Keywords: Pb, Disease profile, Medical burden, Medical big data

\footnotetext{
* Correspondence: chenjingyuan2028@outlook.com

${ }^{\dagger} \mathrm{Han}$ Song and Jianchao Liu contributed equally to this work.

'Department of Health Service, PLA General Hospital, Beijing 100853, China

${ }^{2}$ Department of Occupational and Environmental Health, and the

Ministry-of-Education's Key Laboratory of Hazard Assessment and Control in

Special Operational Environment, School of Public Health, Air Force Medical

University, No.169, Changlexi Road, Xi'an 710032, China
}

(c) The Author(s). 2019 Open Access This article is distributed under the terms of the Creative Commons Attribution 4.0 International License (http://creativecommons.org/licenses/by/4.0/), which permits unrestricted use, distribution, and reproduction in any medium, provided you give appropriate credit to the original author(s) and the source, provide a link to the Creative Commons license, and indicate if changes were made. The Creative Commons Public Domain Dedication waiver (http://creativecommons.org/publicdomain/zero/1.0/) applies to the data made available in this article, unless otherwise stated. 


\section{Background}

Lead $(\mathrm{Pb})$-gasoline has been phased out in China since the 1980s, and was completely banned all over China since 2000 [1]. Though laws were enforced rigorously to remove the use of $\mathrm{Pb}$ sources in commercial, and industrial sectors, in China, $\mathrm{Pb}$ exposure continues to be an important risk factor, affecting almost every organ, and system in the human body [2]. The current mass epidemiological investigations mainly focused on occupational $\mathrm{Pb}$ poisoning, or childhood $\mathrm{Pb}$ exposure [3, 4]. In recent years, medical big data has made it possible to identify the association of $\mathrm{Pb}$ exposure with disease profile based on the massive/large sample size of cross-sectional studies.

$\mathrm{Pb}$ is generally known as a widespread environmental pollutant, and causes a wide range of toxic effects, with no manifest biological roles. Traditional epidemiological studies, by using cross-sectional, case-control, cohort, or case report methods, have elucidated the relations between $\mathrm{Pb}$, and certain kinds of diseases. Their research findings pointed to the association between $\mathrm{Pb}$ exposure and circulatory system diseases, e.g., hypertension, intracerebral hemorrhage, atherosclerosis and acute ischemic stroke [5-7], and a great affinity of the cerebral endothelial cells to $\mathrm{Pb}$ suggested that $\mathrm{Pb}$ concentrations in endothelial cells were much higher than that in other brain cell types [8]. Previous studies also uncovered that vasogenic edema, increased Blood-Brain Barrier (BBB) permeability as well as cerebellar hemorrhage were significant manifestations of $\mathrm{Pb}$-induced damage of microvessels in developing brain $[9,10]$. Nephrotoxicity may occur as a result of $\mathrm{Pb}$ exposure because kidney was the main excretion route, only by which intracorporal $\mathrm{Pb}$ would be eliminated [11]. Chronic Pb exposure at levels above 700-800 $\mu \mathrm{g} / \mathrm{L}$ was an established indicator for chronic kidney disease (CKD) [12]. Proximal tubular cells of the renal tubules accumulated $\mathrm{Pb}$ through specific $\mathrm{Pb}$-binding proteins as the form of typical intracellular inclusions $[13,14]$.

The research subjects of our study are outpatients and inpatients who were required to test blood $\mathrm{Pb}$ concentrations in military hospitals for various symptoms. International Statistical Classification of Diseases, and Related Health Problems (ICD-10) code was implemented by coders of Medical Records Management Division based on doctor's clinical diagnosis [15]. Thus, with this convenience brought by ICD in exchanging and sharing disease information across various hospitals, our study aimed to investigate (1) current status of blood $\mathrm{Pb}$ levels for patients who visited military hospitals; (2) the association of $\mathrm{Pb}$ exposure with the whole diseases' profile, and corresponding medical burden; (3) associations between covariates and blood $\mathrm{Pb}$ levels. The results from this study may help us understand the underlying $\mathrm{Pb}$-induced toxicity in human body system.

\section{Methods}

\section{Study population}

Study population comprises patients receiving whole blood $\mathrm{Pb}$ concentrations test in treatments. The present study was approved by the institutional review boards of Air Force Medical University (Registry no. KY201733461 ), and all studies were conducted in accordance with the ethical principles for medical research involving human subjects as defined in the Declaration of Helsinki. A total number of 294,402 outpatients/inpatients of all military hospitals between 2013 and 2017 were included as subjects by non-probability sampling using SQL expression of Oracle databases. Records lacking in any primary keys, including hospital information, patient's identity, or visiting times, were excluded. Given that China is a country with 56 ethnic groups, we also used the self-report ethnic information to reveal in vivo $\mathrm{Pb}$ heterogeneity levels in different ethnic groups. $\mathrm{Pb}$ content measured by Atomic Absorption Spectroscopy (AAS) in whole blood was expressed as micrograms per liter $(\mu \mathrm{g} / \mathrm{L})$.

\section{Data resource}

This study aims to provide a comprehensive review of medical big data collected from military hospitals, which serves not only the military personnel, but also civilians, taking up a significantly high proportion of Chinese health services. The data was collected in the treatment, which includes patients' demographic information, vital signs, diagnoses of diseases, medical orders, examination reports, lab tests results, drugs, medical supplies or even infections. Patients' information was recorded in the processes of registration, ward management, medical order, auxiliary examination, and even in surgery. Besides, the information flow within departments of each hospital were documented by Admission-Discharge-Transfer (ADT), document entry, drug placement, or medical record cataloging. Medical costs were composed of bed, clinical use of drug, laboratory examination, X-ray, treatment, blood test, operation, nursing care, etc.

\section{Data mining}

Data processing is done by Structured Query Language (SQL) in Oracle database $10 \mathrm{~g}$. Each medical record consists of information including patient's demographic characteristics, vital signs, diagnoses, ADT, surgeries, medical orders, examination reports, lab tests, drugs, medical supplies, medical costs, nursing care, infections, and treatment outcomes. First, we extracted inpatients from this data set, those who had received blood $\mathrm{Pb}$ concentration test in hospitals. The primary key of each patient's record includes hospital code, patient ID, and visit times. Medical costs as well as diagnosis information were included during the analytical process. With a reference to the above indicators, the main diagnostic results, and other important 
information were retrieved from this relational database for further correlation analysis of $\mathrm{Pb}$ exposure.

\section{Study setting}

Data sets from more than 200 military hospitals between 2013 and 2017 were obtained, with each hospital equipped with a Hospital Information System (HIS) for uniformed services as well as similar data dictionary. People's Republic of China (PRC) covers an area of approximately $9,600,000 \mathrm{~km}^{2}$, governing 23 provinces, five autonomous regions, four direct-controlled municipalities (Beijing, Tianjin, Shanghai, and Chongqing), and the special administrative regions of Hong Kong, and Macau. The hospitals in this study are mostly located in the capital cities of these provinces. Patients were labeled with two geographic tags, their birthplaces implicated in their ID card, and the workplace implicated in the postal code of China. We intended to outline $\mathrm{Pb}$ spatial distribution in patients by these two geographic tags.

\section{Statistical analysis}

Our analysis is done on the basis of patients' disease profile, and medical burden of $\mathrm{Pb}$ exposure in more than 100 cities, which are either provincial capitals or cities in key regions, accounting for about $30 \%$ of the major cities in China. Personal profiles were compiled based on demographic factors, including gender, age, or blood types of patients receiving blood $\mathrm{Pb}$ test. We counted $\mathrm{Pb}$ values every single time when patients got $\mathrm{Pb}$ tested for multiple times. Kolmogorov-Smirnov test was employed to identify the distribution of whole blood $\mathrm{Pb}$ concentration, with Q-Q plot applied to visualize the results. To analyze our data by a cross-sectional approach, we evaluated the differences between two independent samples by Wilcoxon rank sum test, or multiple independent samples by Kruskal-Wallis $\mathrm{H}$ test. Medical cost structure was analyzed based on all details of medical expenses. Data were analyzed, or illustrated using GraphPad Prism 6, and Python (version 5.1.0; Anaconda3). Values were considered statistically significant at $p<0.05$.

\section{Results}

\section{Demographic characteristics of patients receiving whole} blood $\mathrm{Pb}$ test

To choose appropriate statistics for $\mathrm{Pb}$, we tested the distribution of whole blood $\mathrm{Pb}$ concentrations among 294,402 patients who received heavy metal blood test. The blood $\mathrm{Pb}$ concentration showed a positively skewed distribution with a mean of $33.71 \mu \mathrm{g} / \mathrm{L}$, yet a median of $28.36 \mu \mathrm{g} / \mathrm{L}$ (Fig. 1-a, b).

\section{Temporal and spatial distribution}

The big data sets were starting to build in 2013. At that time, data size of $\mathrm{Pb}$ tests was only 6802. After that, the data size increased progressively to 92,159 and 94,449 patients in 2016, and 2017, respectively. Along with this data expansion, the median of blood $\mathrm{Pb}$ concentration in patients rose from $22.2 \mu \mathrm{g} / \mathrm{L}$ in 2013 to $29.0 \mu \mathrm{g} / \mathrm{L}$ in 2017 (Fig. 1-c).

Patients born in Hebei $(23,941)$, Shandong $(23,916)$, Inner Mongolia (23,190), Beijing $(17,052)$, but worked in Chongqing (27,347), Beijing (23,901), Hebei $(16,416)$, Shandong $(13,136)$, Liaoning $(12,261)$, Inner Mongolia $(11,133)$, were required to test their $\mathrm{Pb}$ exposure levels (Fig. 1-d, f). Interestingly, blood $\mathrm{Pb}$ concentrations of patients born in Guangxi were the lowest, $4.71 \mu \mathrm{g} / \mathrm{L}$, while that of Yunnan province was the highest, $50 \mu \mathrm{g} / \mathrm{L}$ (Fig. 1-e). Similar to the results of their birthplace, blood $\mathrm{Pb}$ concentrations of patients worked in Guangxi were also the lowest, $2.05 \mu \mathrm{g} / \mathrm{L}$, and patients in Yunnan province was the highest, $56 \mu \mathrm{g} / \mathrm{L}$ (Fig. 1-g).

\section{Blood $\mathrm{Pb}$ levels in various population structures}

Among all the ethnic groups, Han Chinese has the largest population in China, taking up about $96.56 \%$ of the total patients. As for the rest 55 ethnic minorities, Mongolia (2170), Manchu (1848), Hui (914), Tujia (321) accounted for over $80 \%$ (Fig. 2-a). Han Chinese, despite their vast proportion in patients, showed a much lower blood $\mathrm{Pb}$ levels than some other minorities, $27 \mu \mathrm{g} / \mathrm{L}$. Pb concentration of Chuanqing, Uyger, Naxi, Gaoshan, Russian patients, were higher than other groups, with a concentration of $121 \mu \mathrm{g} / \mathrm{L}$, $90 \mu \mathrm{g} / \mathrm{L}, 85.5 \mu \mathrm{g} / \mathrm{L}, 80 \mu \mathrm{g} / \mathrm{L}, 70 \mu \mathrm{g} / \mathrm{L}$ respectively (Fig. 2 -b). Median of Han was $27 \mu \mathrm{g} / \mathrm{L}$, significantly lower than all the other 43 ethnic minorities, $30 \mu \mathrm{g} / \mathrm{L}$ (Fig. 2-c).

Herein, we tried to investigate the geographical characteristics by referring to the birthplace code of Han Chinese, and the minorities. We labeled patients with latitude and longitude according to their birthplace codes in county areas in China. The detailed geographical information of Han patients was shown in Fig. 2d. Meanwhile, Fig. 2e displayed the birthplace information of other 43 minorities by various labels. The majority of Han patients who received blood $\mathrm{Pb}$ test came from Chongqing $(22,037)$, Liaoning $(20,420)$, Shandong $(18,350)$, Inner Mongolia (14,514), Hebei (13,382), Beijing (6044) (Fig. 2-f), whereas over half of minorities patients were born in Beijing $(19,699)$, Hebei (6823), Inner Mongolia (6298) (Fig. 2-h). Blood Pb concentrations of Han patients from Guangxi, Hunan, Gansu, Liaoning were $3.9 \mu \mathrm{g} / \mathrm{L}, 17.9 \mu \mathrm{g} / \mathrm{L}, 19.11 \mu \mathrm{g} / \mathrm{L}, 20 \mu \mathrm{g} / \mathrm{L}$, respectively, which are significantly lower than the other regions, while that of Yunnan province marked the highest, $54 \mu \mathrm{g} / \mathrm{L}$ (Fig. 2-g). Likewise, such geographical characteristics also existed among the ethnic minority groups (Fig. 2-i).

\section{Personal medical burden derived from $\mathrm{Pb}$ exposure}

To identify the economic burden driven by $\mathrm{Pb}$ exposure on individual patients, we calculated average cost per 


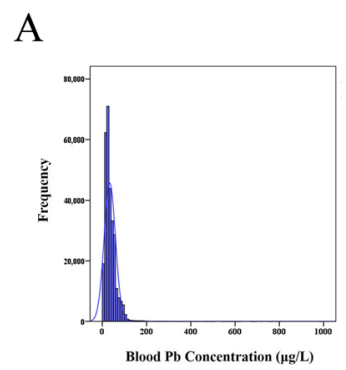

B

C
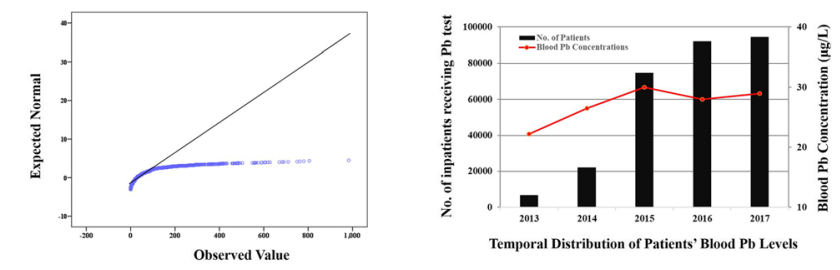

D

E

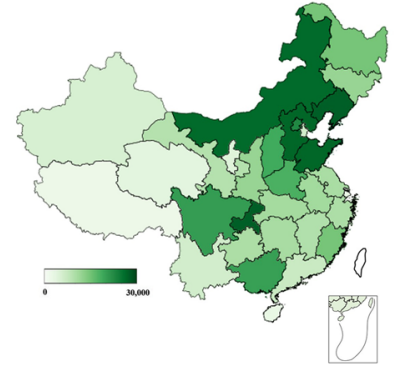

F

G
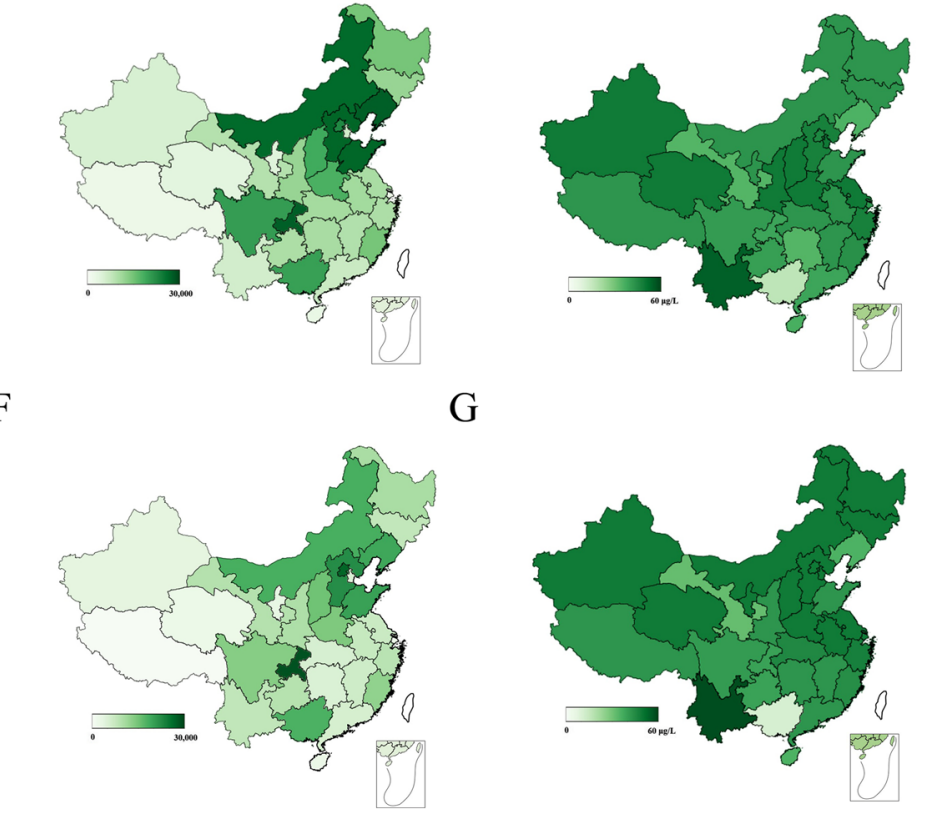

Fig. 1 Temporal, and spatial distribution of patients receiving whole blood lead $(\mathrm{Pb})$ test. a Blood Pb frequency distribution among all the patients. b Patients' Pb distribution test with Q-Q plot. c Amount of data as well as blood Pb concentrations from 2013 to 2017. The red lines indicate the median of blood Pb levels at each year. Bar chart depict the sample size converting from 2013. c and $\mathbf{d}$ Sample size (c), and blood $\mathrm{Pb}$ concentrations $(\mathbf{d})$ indicated with heating map of patients receiving Pb test born in each region in China. e and $\mathbf{f}$ Sample size (e), and blood $\mathrm{Pb}$ concentrations (f) of patients receiving $\mathrm{Pb}$ test worked in each region in China. Color corresponds to number of patients (c, e), or $\mathrm{Pb}$ levels expressed with $\mu \mathrm{g} / \mathrm{L}(\mathbf{d}, \mathbf{f})$

inpatient of 4 major final diagnoses separated by each ICD-10 block. The medical costs were expressed in Chinese Yuan (CNY). The results showed that the block "inpatients with injury, poisoning, and certain other consequences of external causes (S00-T98)" takes up the highest medical cost compared with all the other blocks from first to fourth final diagnosis (Fig. 3-a, b, c, d). As expected, ICD-10 code for $\mathrm{Pb}$ poisoning falls into the subgroup "toxic effects of substances chiefly nonmedicinal as to source (T51-T65)". Thus, we further investigated the diseases based on ICD-10 classification system within the block S00-T98 in the first final diagnosis. Medical burden of different diseases groups were assessed and compared by bubble charts. Blood Pb concentration of T51-T65 were $160.60 \mu \mathrm{g} / \mathrm{L}$, higher than the threshold, $100 \mu \mathrm{g} / \mathrm{L}$, of $\mathrm{Pb}$ poisoning (Fig. 3-e). These inpatients' medical cost may be largely ascribed to their $\mathrm{Pb}$ exposure. Further, within the subgroup T51-T65, specific items were utilized to categorize diseases. Average cost for "Pb poisoning (T56.002)" was $6888 \mathrm{CNY}$ (Fig. 3-f). We further analyzed the structure of medical cost afforded by patients with $\mathrm{Pb}$ poisoning, where drug cost took the large proportion of the medical expenses, 4670 CNY (Fig. 3-g).

\section{Association of $\mathrm{Pb}$ exposure with diseases occurrence}

In an attempt to identify the association between $\mathrm{Pb}$ exposure and diseases occurrence, blood $\mathrm{Pb}$ concentration were recorded based on the major diagnosis separated by ICD-10 blocks. "Neoplasms (C00-D48)" showed relatively lower blood $\mathrm{Pb}$ levels, $25.32 \mu \mathrm{g} / \mathrm{L}$, in the first final diagnosis (Fig. 4-a), but over $50 \mu \mathrm{g} / \mathrm{L}$ in the second, 


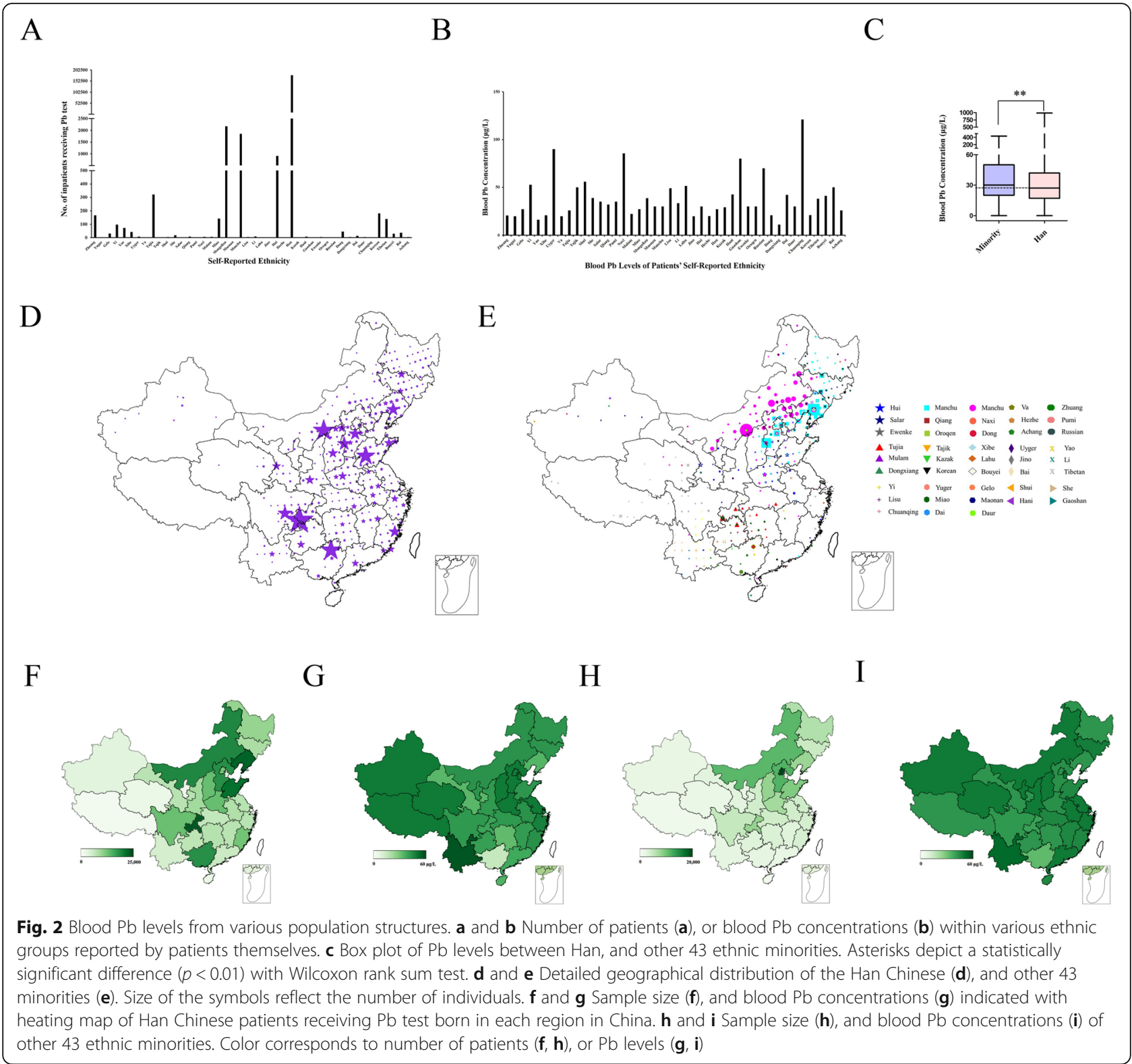

third, and even fourth final diagnosis, far higher than other blocks (Fig. 4-b, c, d). C00-D48 deals with neoplastic conditions including cancer, carcinoma in situ, and benign tumors. Among the C00-D48 group, diseases mostly included "malignant neoplasms, digestive organs (C15C26)", "malignant neoplasms, respiratory system, and intrathoracic organs (C30-C39)", "malignant neoplasms, stated, or presumed to be primary, of lymphoid, haematopoietic, and related tissue (C81-C96)", "benign neoplasms (D10-D36)". However, inpatients with respiratory system and intrathoracic organs disorders (C30-C39) reported the highest $\mathrm{Pb}$ concentrations, $43.32 \mu \mathrm{g} / \mathrm{L}$ (Fig. 4-e). In this subgroup C30-C39, 31 inpatients were reported as "malignant neoplasm of lung (C34.901)" under the specific items (Fig. 4-f). Within the block C00-D48, we compared the differences of C34.901, and non-C34.901 inpatients using non-parametric rank test. Blood $\mathrm{Pb}$ concentrations of C34.901 inpatients, $45.34 \mu \mathrm{g} / \mathrm{L}$, were unexpectedly higher than non-C34.901, 24.00 $\mu \mathrm{g} / \mathrm{L}(\mathrm{z}$-score $=-2.79, p<0.01)$ (Fig. 4-g).

Additionally, the block "factors influencing health status, and contact with health services (Z00-Z99)" also reported higher blood $\mathrm{Pb}$ levels, $51.38 \mu \mathrm{g} / \mathrm{L}$ in second final diagnosis. "Persons with potential health hazards related to family, and personal history, and certain conditions influencing health status (Z80-Z99)" took the most part. Similar to the association between malignant neoplasm and $\mathrm{Pb}$ levels, the median of blood $\mathrm{Pb}$ concentration among patients with "personal history of malignant neoplasm (Z85)" was $51.01 \mu \mathrm{g} / \mathrm{L}$. One patient with "personal history of malignant 
A

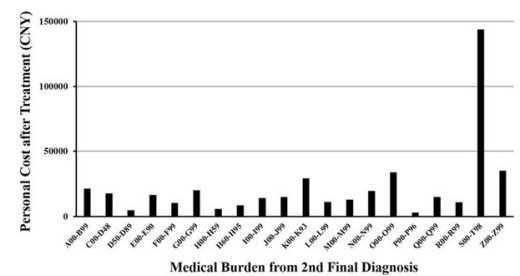

C

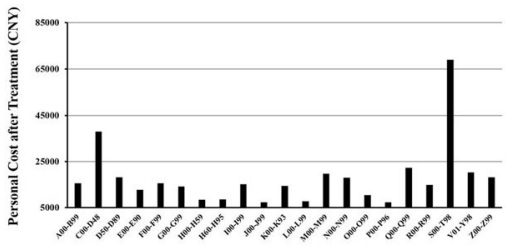

B

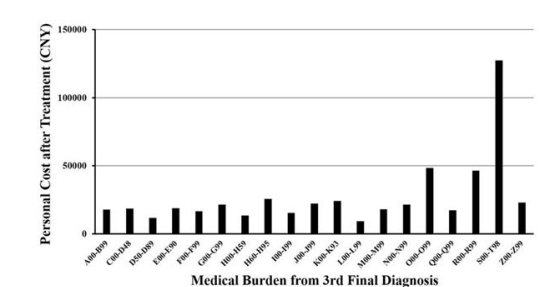

D

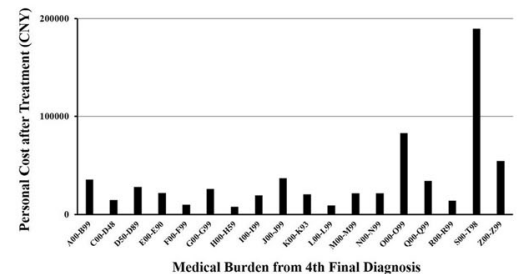

$\mathrm{E}$

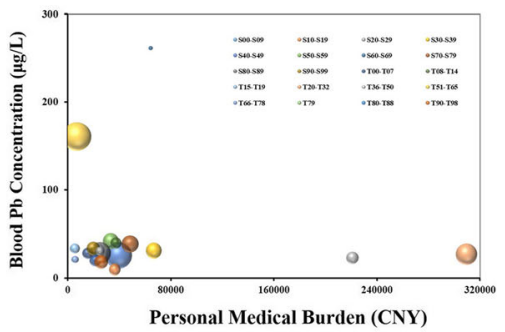

$\mathrm{F}$

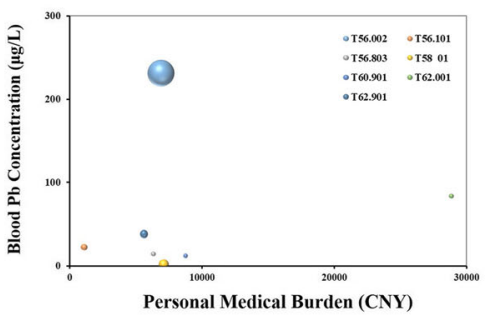

G

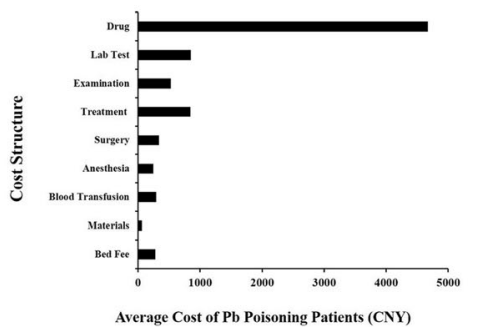

Fig. 3 Personal medical burden after treatment derived from Pb exposure. $\mathbf{a}, \mathbf{b}, \mathbf{c}$, and $\mathbf{d}$ inpatients' medical cost within the ICD-10 block for the first (a), second (b), third (c), and fourth (d) final diagnosis. e Bubble charts of personal medical burden, and blood Pb concentration of subgroups within injury, poisoning, and certain other consequences of external causes (Block S00-T98) for the first final diagnosis. $\mathbf{f}$ Bubble charts of personal medical burden, and blood Pb concentration of specific items with the subgroups (T51-T65). Size of the symbols reflect the number of individuals

neoplasm of trachea, bronchus, and lung (Z85.1)" reported $61.53 \mu \mathrm{g} / \mathrm{L}$ blood $\mathrm{Pb}$ concentration.

Meanwhile, to further elucidate the relation between $\mathrm{Pb}$ exposure and diseases profile, the prevalence rate of inpatients with blood $\mathrm{Pb}$ concentrations higher than 100, or $50 \mu \mathrm{g} / \mathrm{L}$ was calculated. $14.39 \%$ inpatients with S00-T98 reported blood $\mathrm{Pb}$ levels more than $100 \mu \mathrm{g} / \mathrm{L}$, while $29.82 \%$ inpatients were over $50 \mu \mathrm{g} / \mathrm{L}$. Inpatients with blood $\mathrm{Pb}$ levels over $100 \mu \mathrm{g} / \mathrm{L}$ accounted for merely $2.03 \%$ in C00-D48, and 2.92\% in Z00-Z99. However, those whose blood $\mathrm{Pb}$ levels were higher than $50 \mu \mathrm{g} / \mathrm{L}$ accounted for $25.61 \%$ in C00-D48, and 28.33\% in Z00-Z99 (Table 1).

\section{Factors associated with blood Pb levels}

The mean \pm S.D. (range) age of patients in our study was $30 \pm 19(0-100)$ years old at the time of $\mathrm{Pb}$ measurement. Male or female patients accounted for $52.21 \%$ or $47.79 \%$ respectively. The median $\mathrm{Pb}$ levels of male or female patients were $35.31 \mu \mathrm{g} / \mathrm{L}$ or $29.70 \mu \mathrm{g} / \mathrm{L}$, respectively. To identify the factors influencing $\mathrm{Pb}$ levels among inpatients, statistical differences of blood $\mathrm{Pb}$ concentrations were analyzed based on demographic factors. Except for blood type $(A B O)$, significant difference was found among other six factors including gender, age, ethnic group, blood type $(\mathrm{Rh})$, visit times, and treatment results. Male inpatients' $\mathrm{Pb}$ levels was significantly higher than female (z-score $=-7.40$, $p<0.01)$. Age group of 18 to 45 reported the highest $\mathrm{Pb}$ levels, compared with other groups. Pb levels of minority groups, $24.30 \mu \mathrm{g} / \mathrm{L}$, were significantly higher than that of the Han inpatients, $20.21 \mu \mathrm{g} / \mathrm{L}(\mathrm{z}$-score $=-38.54, p<0.01)$. $\mathrm{Pb}$ concentration of blood $\mathrm{Rh}$ negative-type was higher than positive-type (z-score $=-7.05, \quad p<0.01)$, but similar differences were not observed in the ABO blood types $\left(x^{2}=6.54, p>0.05\right)$. Those who were initially hospitalized 


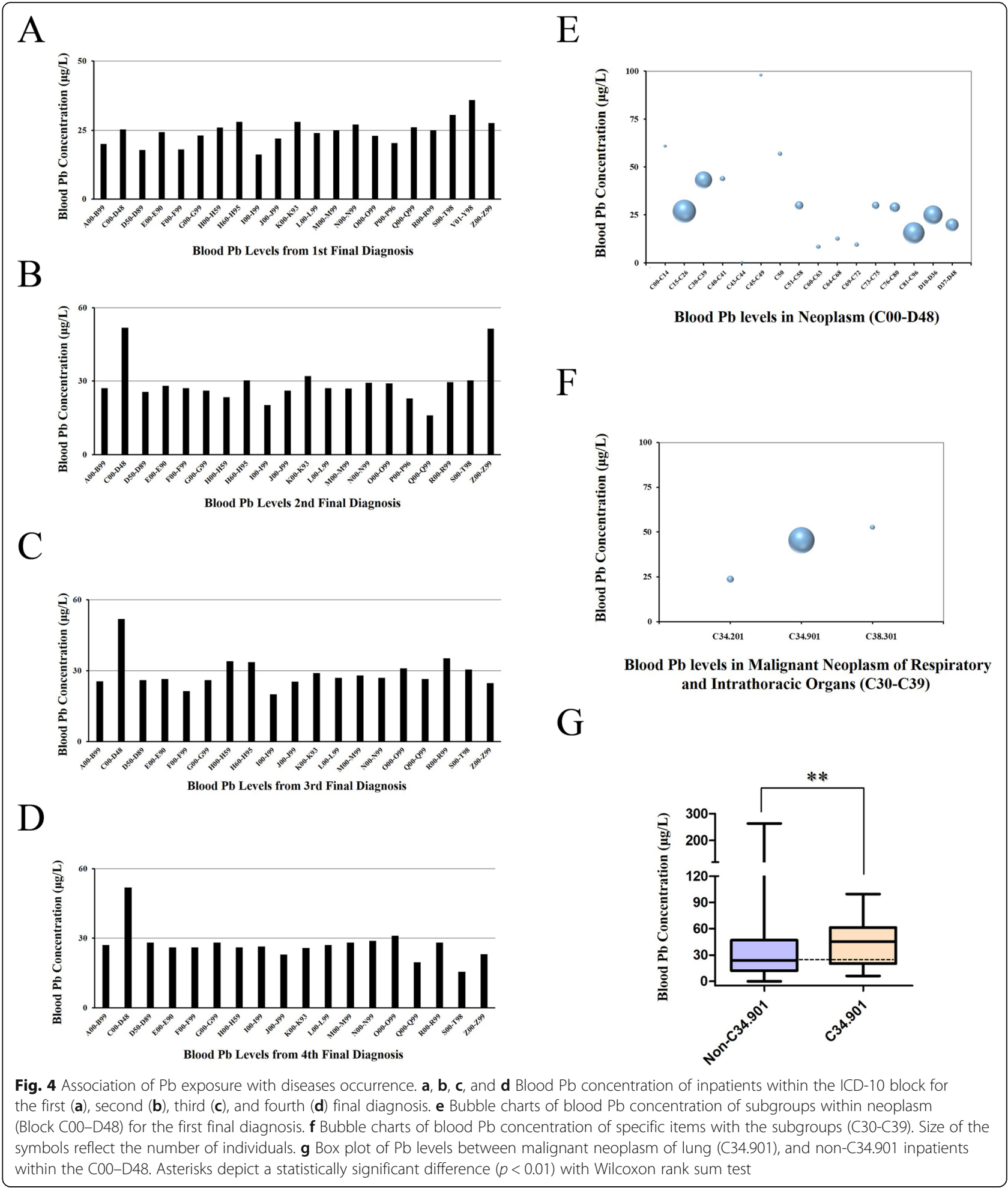

reported blood $\mathrm{Pb}$ concentrations $24.00 \mu \mathrm{g} / \mathrm{L}$, whereas those who were hospitalized more than twice reported a concentration of $19.11 \mu \mathrm{g} / \mathrm{L}$. In terms of treatment results, $\mathrm{Pb}$ levels of cured, or improved inpatients were lower than invalid, untreated, or others $\left(x^{2}=213.66, p<0.01\right)$ (Table 2).

After separating each demographic factor, we also measured $\mathrm{Pb}$ concentration between $\mathrm{C} 34.901$, and non- 
Table 1 Diseases spectrum (ICD-10 Blocks) and prevalence rate of inpatients with blood Pb concentrations higher than 100 or $50 \mu \mathrm{g} / \mathrm{L}$

\begin{tabular}{|c|c|c|c|c|c|c|}
\hline Blocks & Diseases spectrum & $\begin{array}{l}\text { Inpatients } \\
\text { with } \mathrm{Pb} \text { tests }\end{array}$ & $\geq 100 \mu \mathrm{g} / \mathrm{L}$ & Percentage (\%) & $\geq 50 \mu \mathrm{g} / \mathrm{L}$ & Percentage (\%) \\
\hline A00-B99 & Certain infectious and parasitic diseases & 576 & 9 & $1.56 \%$ & 77 & $13.37 \%$ \\
\hline C00-D48 & Neoplasms & 246 & 5 & $2.03 \%$ & 63 & $25.61 \%$ \\
\hline D50-D89 & $\begin{array}{l}\text { Diseases of the blood and blood-forming organs and certain } \\
\text { disorders involving the immune mechanism }\end{array}$ & 252 & 3 & $1.20 \%$ & 34 & $13.55 \%$ \\
\hline E00-E90 & Endocrine, nutritional and metabolic diseases & 545 & 14 & $2.57 \%$ & 93 & $17.06 \%$ \\
\hline F00-F99 & Mental and behavioural disorders & 310 & 3 & $0.97 \%$ & 29 & $9.35 \%$ \\
\hline G00-G99 & Diseases of the nervous system & 1058 & 24 & $2.27 \%$ & 168 & $15.88 \%$ \\
\hline $100-199$ & Diseases of the circulatory system & 1955 & 25 & $1.28 \%$ & 167 & $8.54 \%$ \\
\hline J00-J99 & Diseases of the respiratory system & 3159 & 27 & $0.86 \%$ & 543 & $17.22 \%$ \\
\hline K00-K93 & Diseases of the digestive system & 1273 & 76 & $5.97 \%$ & 313 & $24.59 \%$ \\
\hline M00-M99 & Diseases of the musculoskeletal system and connective tissue & 349 & 8 & $2.31 \%$ & 59 & $17.00 \%$ \\
\hline No0-N99 & Diseases of the genitourinary system & 193 & 9 & $4.66 \%$ & 39 & $20.21 \%$ \\
\hline R00-R99 & $\begin{array}{l}\text { Symptoms, signs and abnormal clinical and laboratory findings, } \\
\text { not elsewhere classified }\end{array}$ & 249 & 18 & $7.23 \%$ & 56 & $22.49 \%$ \\
\hline S00-T98 & Injury, poisoning and certain other consequences of external causes & 285 & 41 & $14.39 \%$ & 85 & $29.82 \%$ \\
\hline Z00-Z99 & Factors influencing health status and contact with health services & 242 & 7 & $2.92 \%$ & 68 & $28.33 \%$ \\
\hline
\end{tabular}

Table 2 Blood Pb levels at demographic factors, further in C34.901 or non-C34.901 among C00-D48 inpatients

\begin{tabular}{|c|c|c|c|c|c|c|c|c|}
\hline \multicolumn{2}{|c|}{ Categorical Variables } & \multirow{2}{*}{$\frac{\text { No. }}{7645}$} & \multirow{2}{*}{$\begin{array}{l}\text { Percentage (\%) } \\
57.23 \%\end{array}$} & \multirow{2}{*}{$\frac{\mathrm{Pb} \text { levels }}{22.00}$} & \multirow{2}{*}{$\frac{p \text {-value }}{p<0.01}$} & \multirow{2}{*}{$\frac{\text { Statistics }}{-7.40^{\mathrm{a}}}$} & \multirow{2}{*}{$\frac{\text { No. of C34.901 (Pb levels) }}{15(50.20)}$} & \multirow{2}{*}{$\frac{\text { No. of non-C34.901 (Pb levels) }}{101(24.00)}$} \\
\hline Gender & Male & & & & & & & \\
\hline & Female & 5713 & $42.77 \%$ & 20.00 & & & $15(36.80)$ & 105 (23.98) \\
\hline \multirow[t]{4}{*}{ Age } & $<18$ & 5042 & $37.83 \%$ & 24.22 & $p<0.01$ & $596.34^{\mathrm{b}}$ & - & $14(24.50)$ \\
\hline & $18-45$ & 2581 & $19.37 \%$ & 25.00 & & & $1(6.20)$ & $52(19.00)$ \\
\hline & $45-60$ & 1839 & $13.80 \%$ & 24.20 & & & $8(53.03)$ & $68(26.92)$ \\
\hline & $>60$ & 3866 & $29.01 \%$ & 16.00 & & & $21(45.34)$ & $78(22.00)$ \\
\hline \multirow[t]{2}{*}{ Ethnic group } & Han & 12,762 & $95.17 \%$ & 20.21 & $p<0.01$ & $-38.54^{\mathrm{a}}$ & $30(46.44)$ & 205 (23.98) \\
\hline & Minority & 647 & $4.83 \%$ & 24.30 & & & - & $7(25.60)$ \\
\hline \multirow[t]{4}{*}{ Blood type (ABO) } & $A$ & 1550 & $27.87 \%$ & 20.00 & $p>0.05$ & $6.54^{\mathrm{b}}$ & $3(47.53)$ & $48(20.85)$ \\
\hline & B & 1696 & $30.49 \%$ & 19.29 & & & $4(25.11)$ & $36(25.00)$ \\
\hline & $\mathrm{O}$ & 1806 & $32.47 \%$ & 20.11 & & & $2(33.47)$ & $50(20.50)$ \\
\hline & $A B$ & 510 & $9.17 \%$ & 19.20 & & & $4(32.75)$ & $9(37.14)$ \\
\hline \multirow[t]{2}{*}{ Blood type (Rh) } & Negative & 73 & $1.47 \%$ & 43.47 & $p<0.01$ & $-7.05^{\mathrm{a}}$ & $2(72.45)$ & 0 \\
\hline & Positive & 4892 & $98.53 \%$ & 19.33 & & & $13(36.00)$ & $131(21.00)$ \\
\hline \multirow[t]{2}{*}{ Visit times } & First & 6770 & $50.49 \%$ & 24.00 & $p<0.01$ & $-12.42^{a}$ & $13(56.67)$ & $115(26.00)$ \\
\hline & Not first & 6638 & $49.51 \%$ & 19.11 & & & $17(30.00)$ & $98(20.55)$ \\
\hline \multirow[t]{6}{*}{ Treatment results } & Cured & 4890 & $36.56 \%$ & 24.00 & $p<0.01$ & $213.66^{\mathrm{b}}$ & $2(43.91)$ & $47(25.00)$ \\
\hline & Improved & 7800 & $58.31 \%$ & 19.39 & & & $8(16.65)$ & $127(22.00)$ \\
\hline & Invalid & 41 & $0.31 \%$ & 25.00 & & & - & - \\
\hline & Untreated & 112 & $0.84 \%$ & 26.00 & & & $1(36.00)$ & $9(20.20)$ \\
\hline & Died & 55 & $0.41 \%$ & 23.00 & & & $3(15.11)$ & $3(32.00)$ \\
\hline & Others & 479 & $3.58 \%$ & 33.80 & & & $16(56.67)$ & 27 (39.54) \\
\hline
\end{tabular}

C34.901, Malignant Neoplasm of Lung

C00-D48, Neoplasms

a Z-score of two independent samples by Wilcoxon rank sum test

${ }^{\mathrm{b}}$ Chi-Squared values $\left(\mathrm{X}^{2}\right)$ of multiple independent samples by Kruskal-Wallis $\mathrm{H}$ test 
C34.901 within the block C00-D48 inpatients. C34.901 exceeded non-C34.901 in both male $(50.20 \mu \mathrm{g} / \mathrm{L}$ vs $24.00 \mu \mathrm{g} / \mathrm{L})$ and female patients $(36.80 \mu \mathrm{g} / \mathrm{L}$ vs $23.98 \mu \mathrm{g} / \mathrm{L})$ and only one C34.901 patient was reported younger than 45 years old. Interestingly, no significant differences were found between $\mathrm{ABO}$ blood types. The concentration of C34.901 patients with blood type $A, O, A B$ were far higher than that of non-C34.901, while two groups with type $B$ reported much close figures. In regard to the treatment results, cured C34.901 inpatients' Pb levels, though with only two patients, markedly surpassed the improved, invalid, or untreated (Table 2).

\section{Discussion}

In the present study, we investigated the blood $\mathrm{Pb}$ levels among the a massive number of patients with various diseases, and found that: (1) the average blood $\mathrm{Pb}$ concentrations of Chinese patients was $28.36 \mu \mathrm{g} / \mathrm{L}$; (2) obvious geographical differences existed in blood Pb levels; (3) Han Chinese patients' $\mathrm{Pb}$ levels were significantly lower than other minorities groups; (4) $\mathrm{Pb}$ exposure may be an important risk factor for malignant neoplasm of lung, considering the significantly higher $\mathrm{Pb}$ levels in lung cancer than other respiratory, and intrathoracic organs.

Compared with the blood $\mathrm{Pb}$ levels reported in previous research targeting occupational populations [4], children [3], or adults [16], Chinese patients as a whole, reported the lowest $\mathrm{Pb}$ levels, which to some extent represents conditions of residence throughout China. The findings may also be attributed to differences in the age structures of all the subjects. About $30 \%$ patients were over 60 years old, and their $\mathrm{Pb}$ concentration was the lowest compared with the rest three groups, $16.00 \mu \mathrm{g} / \mathrm{L}$.

This study revealed the geographical differences of blood $\mathrm{Pb}$ levels in patients who visited hospitals, which could partially represent general population in China [1, 17]. Systematic review of published papers illustrated that, of 24 provinces, or regions, only 4 provinces (Hunan, Guangdong, Gansu, Jiangxi) showed a trend of increased mean blood $\mathrm{Pb}$ levels, and the prevalence of $\mathrm{Pb}$ poisoning [18]. However, two adjacent provinces, namely, Yunnan, and Guangxi Zhuang Autonomous Region, showed opposite trend in our survey, with Yunnan being the highest, and Guangxi the lowest. Similar results were observed not only in birthplace, but also in workplace, suggesting career as a factor related to $\mathrm{Pb}$ exposure. The fact that Yunnan has long been taking the first place in deposits of heavy metals may account for the $\mathrm{Pb}$ accumulation of patients born or worked in Yunnan [19]. Meanwhile, patients from Guangxi mainly dwelled in Guilin, a prefecture in the far south of China. This huge contrast of patients' $\mathrm{Pb}$ levels between two regions may result from the heterogeneity of their living environment.
China is a multi-ethnic country. Han Chinese, as the majority, showed a significantly lower blood $\mathrm{Pb}$ levels than other minorities. The difference between Han group, and other groups has been pointed out in previous study, reporting a mean blood Pb levels of $55.70 \mu \mathrm{g} /$ $\mathrm{L}, 53.00 \mu \mathrm{g} / \mathrm{L}$ in Uyger, and Han children, respectively [20]. This difference in $\mathrm{Pb}$ levels may be attributed to the varied living, and eating habits of ethnic groups. Remarkably, patients with $\mathrm{Rh}$ negative blood type seemed to accumulate more $\mathrm{Pb}$ than $\mathrm{Rh}$ positive. Blood serves as an important medium for $\mathrm{Pb}$ transport. More than $99 \%$ of blood $\mathrm{Pb}$ stays with red cells, while the rest is distributed in plasma [21]. Rh proteins form a core complex which is critical to the structure of the erythrocyte membrane [22], and might affect the sequestration, or excretion of $\mathrm{Pb}$ between red cells, and blood. Interestingly, $\mathrm{Pb}$ levels became lower when patients were hospitalized for a longer time. This may be attributed to medical interventions, professional health education, and guidance on behavior or nutrition from doctors during treatment.

In 2016, $\mathrm{Pb}$ exposure accounted for 540, 000 deaths and 13.9 million years of healthy life lost (disability adjusted life years, DALYs) worldwide due to long-term effects on health [23]. An environmentally attributable fraction model was used to estimate $\mathrm{Pb}$-attributable total economic costs, \$227.7 billion in Eastern Asia (China, Mongolia), represented by each 1-year cohort of children $<5$ years of age [24]. DALYs are particularly useful for prioritizing public health interventions, meanwhile, total economic cost is used as a tool to assess medical burdens of a country or an area. Our study discovered that the average medical cost due to $\mathrm{Pb}$ poisoning was 6888 $\mathrm{CNY}$, of which drug cost took the largest proportion, $4670 \mathrm{CNY}$. These findings suggested that the treatment of $\mathrm{Pb}$ poisoning, especially drug treatment, may be the major resource of medical burden for patients under $\mathrm{Pb}$ exposure, and average medical cost needs to be considered when assessing personal economic burden of residents, especially those in developing countries or areas.

Almost all the previous studies on the association between $\mathrm{Pb}$ exposure and lung cancer had $\mathrm{Pb}$ workers (among battery, or smelter workers) as their subjects. Besides, some studies reported confusing and even contradictory results on the associations. The estimated risk for lung cancer, as is commonly agreed, were elevated in $\mathrm{Pb}$-only workers compared with other workers [25]. However, in two population-based case-control studies, investigators observed no increased risk of lung cancer with exposure to $\mathrm{Pb}$ compounds [26]. The present study further confirmed the association of $\mathrm{Pb}$ exposure with lung cancer among residents, in addition to occupational workers. However, the findings are limited because other possible factors affecting lung cancer risks were not considered. 
This study reported a blood $\mathrm{Pb}$ concentration of $24.22 \mu \mathrm{g} / \mathrm{L}$ in patients under 18 years old. Teenagers, especially children, in their growth period, are sensitive to $\mathrm{Pb}$ exposure, which impairs their cognitive function, mental behavior, infant growth, or even influences future socioeconomic status [16, 27-29]. Guide issued by Ministry of Health to preventive measures against child-related high blood $\mathrm{Pb}$ levels and $\mathrm{Pb}$ poisoning set upper limit for children at $100 \mu \mathrm{g} / \mathrm{L}$ in China. However, Centers for Disease Control and Prevention (CDC) in America has set the upper limit for children at $50 \mu \mathrm{g} / \mathrm{L}$ in 2012. Therefore, we highly recommend that the critical value of blood $\mathrm{Pb}$ poisoning, especially for children, should be restricted to $50 \mu \mathrm{g} / \mathrm{L}$ in China.

Admittedly, this study has some limitations. Although we intended to investigate the current status of blood $\mathrm{Pb}$ levels all over China, there, to some extent, still existed flaws or loopholes in population selection. Those who have never tested their blood $\mathrm{Pb}$ concentration were not included in this study. The conclusion of the study representing whole population needs further verification. Furthermore, this study is not a case-control or cohort study in terms of methodology. Some conclusions, such as $\mathrm{Pb}$ as risk factor for lung cancer, need to be further verified in cohort study, or basic research. Finally, all data were limited in the HIS databases in the hospitals. Connections with patients' other datasets outside hospitals will facilitate, and extend research of $\mathrm{Pb}$ exposure on human bodies.

\section{Conclusions}

In summary, this study reported current status of blood $\mathrm{Pb}$ levels, its effects on diseases' profile, and medical burden for patients who visited military hospitals, partially representing the whole Chinese populations. Despite the Chinese government's efforts to control the environmental $\mathrm{Pb}$ level, $\mathrm{Pb}$ poisoning was still imposing the direct economic burdens on patients because of $\mathrm{Pb}$ exposure. From the perspectives of diseases occurrence, the association of $\mathrm{Pb}$ with lung cancer may open up new areas for $\mathrm{Pb}$-induced toxicology, providing a basis for the government and public health departments to further control $\mathrm{Pb}$ levels. In summary, these findings reveal a novel insight into future toxicology research from the aspect of data mining techniques.

\footnotetext{
Abbreviations

AAS: Atomic Absorption Spectroscopy; ADT: Admission-Discharge-Transfer; BBB: Blood-Brain Barrier; CDC: Centers for Disease Control and Prevention; CKD: Chronic Kidney Disease; DALYs: Disability Adjusted Life Years; EMR: Electronic Medical Record; HIS: Hospital Information System; ICD: International Statistical Classification of Diseases, and Related Health Problems; Pb: Lead; PRC: People's Republic of China; SQL: Structured Query Language
}

Acknowledgements

We thank Qing-Yi, Wang for English improving.

\section{Authors' contributions}

HS and WL designed the study. HS collected and analyzed the data and drafted the manuscript. $J$ collected data and provided expert statistical advice. HS and ZC researched and collected articles. JC provided medical big data support and research advice. All authors were involved in editing of the manuscript, and read and approved the final version.

\section{Funding}

This work was supported by the National Key Research and Development Plan [grant number 2017YFC1307705]. The funders did not have any role in the design of the study and collection, analysis, and interpretation of data and in writing the manuscript.

\section{Availability of data and materials}

The data that support the findings of this study are available from Directorate of Medical Services, Logistics Support Department of PLA, but restrictions apply to the availability of these data, which were used under license for the current study, and so are not publicly available. Data are however available from the authors upon reasonable request and with permission of Directorate of Medical Services, Logistics Support Department of PLA.

\section{Ethics approval and consent to participate}

The present study was approved by the institutional review boards of Air Force Medical University (Registry no. KY20173346-1), and all studies were conducted in accordance with the ethical principles for medical research involving human subjects as defined in the Declaration of Helsinki. The consent to participate has been reviewed by the institutional review boards. This study used historical data and the consent may bring population selection bias. Patients' privacies have been eliminated before data analyses. This study was deemed minimal risk by the boards and waiver of consent was approved.

\section{Consent for publication}

Not applicable.

\section{Competing interests}

The authors declare that they have no competing interests.

Received: 5 May 2019 Accepted: 19 August 2019

Published online: 27 August 2019

References

1. Han Z, Guo X, Zhang B, Liao J, Nie L. Blood lead levels of children in urban and suburban areas in China (1997-2015): temporal and spatial variations and influencing factors. Sci Total Environ. 2018;625:1659-66.

2. Boskabady M, Marefati N, Farkhondeh T, Shakeri F, Farshbaf A, Boskabady $\mathrm{MH}$. The effect of environmental lead exposure on human health and the contribution of inflammatory mechanisms, a review. Environ Int. 2018;120: 404-20.

3. Canfield RL, Henderson CJ, Cory-Slechta DA, Cox C, Jusko TA, Lanphear BP Intellectual impairment in children with blood lead concentrations below 10 microg per deciliter. N Engl J Med. 2003;348(16):1517-26.

4. Devoz PP, Gomes WR, De Araujo ML, Ribeiro DL, Pedron T, Greggi AL, Batista BL, Barbosa FJ, Barcelos G. Lead (Pb) exposure induces disturbances in epigenetic status in workers exposed to this metal. J Toxicol Environ Health A. 2017:80(19-21):1098-105.

5. Gambelunghe A, Sallsten G, Borne Y, Forsgard N, Hedblad B, Nilsson P, Fagerberg B, Engstrom G, Barregard L. Low-level exposure to lead, blood pressure, and hypertension in a population-based cohort. Environ Res. 2016; 149:157-63.

6. Navas-Acien A, Selvin E, Sharrett AR, Calderon-Aranda E, Silbergeld E, Guallar E. Lead, cadmium, smoking, and increased risk of peripheral arterial disease. Circulation. 2004;109(25):3196-201.

7. Menke A, Muntner P, Batuman V, Silbergeld EK, Guallar E. Blood lead below $0.48 \mathrm{micromol} / \mathrm{L}$ (10 microg/dL) and mortality among US adults. Circulation. 2006;114(13):1388-94.

8. Toews AD, Kolber A, Hayward J, Krigman MR, Morell P. Experimental lead encephalopathy in the suckling rat: concentration of lead in cellular fractions enriched in brain capillaries. Brain Res. 1978;147(1):131-8.

9. Hossain MA, Russell JC, Miknyoczki S, Ruggeri B, Lal B, Laterra J. Vascular endothelial growth factor mediates vasogenic edema in acute lead encephalopathy. Ann Neurol. 2004;55(5):660-7. 
10. Song H, Zheng G, Shen XF, Liu XQ, Luo WJ, Chen JY. Reduction of brain barrier tight junctional proteins by lead exposure: role of activation of nonreceptor tyrosine kinase Src via chaperon GRP78. Toxicol Sci. 2014; 138(2):393-402.

11. Zhang J, Cao H, Zhang Y, Zhang Y, Ma J, Wang J, Gao Y, Zhang X, Zhang F, Chu L. Nephroprotective effect of calcium channel blockers against toxicity of lead exposure in mice. Toxicol Lett. 2013;218(3):273-80.

12. Ekong $E B$, Jaar $B G$, Weaver VM. Lead-related nephrotoxicity: a review of the epidemiologic evidence. Kidney Int. 2006;70(12):2074-84.

13. Oskarsson A, Fowler BA. Effects of lead inclusion bodies on subcellular distribution of lead in rat kidney: the relationship to mitochondrial function. Exp Mol Pathol. 1985;43(3):397-408.

14. Egle PM, Shelton KR. Chronic lead intoxication causes a brain-specific nuclear protein to accumulate in the nuclei of cells lining kidney tubules. J Biol Chem. 1986;261(5):2294-8.

15. Chen Y, Lu H, Li L. Automatic ICD-10 coding algorithm using an improved longest common subsequence based on semantic similarity. PLoS One. 2017;12(3):e173410.

16. Reuben A, Caspi A, Belsky DW, Broadbent J, Harrington H, Sugden K, Houts RM, Ramrakha S, Poulton R, Moffitt TE. Association of childhood blood lead levels with cognitive function and socioeconomic status at age 38 years and with IQ change and socioeconomic mobility between childhood and adulthood. JAMA. 2017;317(12):1244-51.

17. Sun X, Li X, Liu D, Yang T, Zhao Y, Wu T, Cai Y, Ai Y, Zhang X, Wang J, Yang $R, Y u H$, Mielke HW. Use of a survey to assess the environmental exposure and family perception to lead in children ( $<6$ Years) in Four Valley Cities, Northwestern China. Int J Environ Res Public Health. 2018;15(4):740.

18. He K, Wang S, Zhang J. Blood lead levels of children and its trend in China. Sci Total Environ. 2009:407(13):3986-93.

19. Wang Y, Wang R, Fan L, Chen T, Bai Y, Yu Q, Liu Y. Assessment of multiple exposure to chemical elements and health risks among residents near Huodehong lead-zinc mining area in Yunnan, Southwest China. Chemosphere. 2017;174:613-27.

20. Chen Y, Zhao JX, Liu JW, Cui J, Li L, Tian W. Lack of association of deltaaminolevulinic acid dehydratase genotype with blood lead levels in environmentally exposed children of Uygur and Han populations. Acta Paediatr. 2008;97(12):1717-20

21. Smith D, Hernandez-Avila M, Tellez-Rojo MM, Mercado A, Hu H. The relationship between lead in plasma and whole blood in women. Environ Health Perspect. 2002;110(3):263-8.

22. Westhoff $\mathrm{CM}$. The structure and function of the Rh antigen complex. Semin Hematol. 2007;44(1):42-50.

23. Institute for Health Metrics and Evaluation (IHME). GBD Compare. Seattle: IHME, University of Washington; 2016. http://vizhub.healthdata.org/gbdcompare, Accessed 18 July 2018

24. Attina TM, Trasande L. Economic costs of childhood lead exposure in low- and middle-income countries. Environ Health Perspect. 2013;121(9):1097-102.

25. Lundstrom NG, Nordberg G, Englyst V, Gerhardsson L, Hagmar L, Jin T, Rylander L, Wall S. Cumulative lead exposure in relation to mortality and lung cancer morbidity in a cohort of primary smelter workers. Scand I Work Environ Health. 1997;23(1):24-30.

26. Wynant W, Siemiatycki J, Parent ME, Rousseau MC. Occupational exposure to lead and lung cancer: results from two case-control studies in Montreal Canada. Occup Environ Med. 2013;70(3):164-70.

27. Taylor CM, Kordas K, Golding J, Emond AM. Effects of low-level prenatal lead exposure on child IQ at 4 and 8 years in a UK birth cohort study. Neurotoxicology. 2017;62:162-9.

28. Luo W, Ruan D, Yan C, Yin S, Chen J. Effects of chronic lead exposure on functions of nervous system in Chinese children and developmental rats. Neurotoxicology. 2012;33(4):862-71.

29. Ji A, Wang F, Luo W, Yang R, Chen J, Cai T. Lead poisoning in China: a nightmare from industrialisation. Lancet. 2011;377(9776):1474-6.

\section{Publisher's Note}

Springer Nature remains neutral with regard to jurisdictional claims in published maps and institutional affiliations.

Ready to submit your research? Choose BMC and benefit from:

- fast, convenient online submission

- thorough peer review by experienced researchers in your field

- rapid publication on acceptance

- support for research data, including large and complex data types

- gold Open Access which fosters wider collaboration and increased citations

- maximum visibility for your research: over $100 \mathrm{M}$ website views per year

At BMC, research is always in progress.

Learn more biomedcentral.com/submissions 